\title{
Web-Based and mHealth Technologies to Support Self-Management in People Living With Type 2 Diabetes: Validation of the Diabetes Self-Management and Technology Questionnaire (DSMT-Q)
}

Laura Kelly $^{1,2}$, BA, MSc, DPhil; Crispin Jenkinson ${ }^{1,2}$, DPhil; David Morley ${ }^{1,2}, \mathrm{PhD}$

${ }^{1}$ Health Services Research Unit, Nuffield Department of Population Health, University of Oxford, Oxford, United Kingdom
${ }^{2}$ Harris Manchester College, Oxford, United Kingdom

\section{Corresponding Author:}

Laura Kelly, BA, MSc, DPhil

Health Services Research Unit

Nuffield Department of Population Health

University of Oxford

Old Road Campus

Oxford, OX3 7LF

United Kingdom

Phone: 44 (0)1865 289425

Email: 1aura.kelly@ndph.ox.ac.uk

\section{Abstract}

Background: A growing number of web-based and mobile health (mHealth) technologies have been developed to support type 2 diabetes self-management. Little is known about individuals' experiences with these technologies and how they support self-management. Appropriate tools are needed to understand how web-based and mHealth interventions may impact self-management.

Objective: This study aimed to develop an instrument, the Diabetes Self-Management and Technology Questionnaire (DSMT-Q), to assess self-management among people living with type 2 diabetes who use web-based and mHealth technologies.

Methods: A total of 36 candidate questionnaire items, drafted previously, were refined using cognitive debriefing interviews $(n=8)$, expert consultation, and public patient involvement feedback. Item reduction steps were performed on survey data $(n=250)$, and tests of validity and reliability were subsequently performed.

Results: Following amendments, patients and experts found 21 items relevant and acceptable for inclusion in the instrument. Survey participants included 104 (41.6\%) women and 146 (58.4\%) men. Two subscales with high construct validity, internal consistency, and test-retest reliability were identified: "Understanding individual health and making informed decisions" and "Confidence to reach and sustain goals."

Conclusions: Analyses confirmed good psychometric properties in the DSMT-Q scales. This tool will facilitate the measurement of self-management in people living with type 2 diabetes who use web-based or mHealth technologies.

(JMIR Diabetes 2020;5(3):e18208) doi: 10.2196/18208

\section{KEYWORDS}

mHealth; self-care; type 2 diabetes; self-monitoring; questionnaire

\section{Introduction}

In 2018, just over 3.8 million people in the United Kingdom were diagnosed with diabetes [1], an increase of 2.4 million since 1996 [2]. A total of $90 \%$ of those diagnosed with diabetes are thought to have type 2 diabetes (diabetes mellitus), with a further 1 million estimated to be unaware they have the condition [2]. Complications that may need to be managed include gastroparesis, painful diabetic neuropathy, autonomic neuropathy, foot problems, kidney disease, erectile dysfunction, and eye disease [3]. Complications arising from this long-term condition can be avoided mainly through supporting patients to manage their condition through, for example, through 
achieving glycemic control, through education and/or through lifestyle changes. Nevertheless, they are estimated to cost the National Health Service over GBP $£ 7$ billion (US $\$ 8.7$ billion) per year in direct costs [4].

People living with type 2 diabetes need to be supported to manage their condition, improve well-being, and prevent diabetes-related complications from arising. Key management priorities for UK health services include patient education, dietary advice, blood glucose management, and drug treatment [3]. While some areas of routine care (for example, therapy changes) may need to be implemented during face-to-face interactions, digital health care can also be adopted outside these interactions (for example, when promoting adherence and providing peer support) [5]. Some evidence indicates that web-based and mHealth technologies can be used successfully to enable patients to access information, individualize management, track progress and reach personalized goals and, facilitate communication with health professionals or peers [6]. The use of technology has led to improvements in physical activity, diet, problem-solving, and blood glucose control [7-12]; however, some evidence suggests that there may be aspects of self-care that are best-supported face-to-face [13]. In the long term, it may be that self-management technologies (for example, a mobile app targeting blood glucose control), are most effective when they are used interactively with a professional health care team [14].

Despite the availability of many mHealth self-management technologies, minimal evidence exists around their effectiveness, particularly concerning longer-term outcomes [15]. Evaluations of mobile apps aimed at encouraging behavior change predominantly focus on content evaluation and few measure effectiveness [16]. This gap is particularly evident for diabetes-related apps where content or usability is typically evaluated using self-developed checklists or through user feedback [16]. Many instruments used to measure the effectiveness of diabetes-related web-based or mHealth interventions have poor psychometric properties, do not meet guidelines promoted by regulatory bodies (for example, by not including the patient during development $[17,18]$ ) and may lack sensitivity to the effects of web-based and mHealth technologies as they were developed before their existence [8].

Assessing the effectiveness of technologies supporting self-management requires suitable instruments that (1) are appropriate for use with people living with type 2 diabetes, (2) includes user perspectives throughout development, and (3) is sensitive to the impact of web-based and mHealth technologies. A truly useful instrument would also be suitable for use in a comparator group not receiving the intervention. This study, therefore, aimed to develop a new measure, the Diabetes Self-Management and Technology Questionnaire (DSMT-Q), to assess self-management among people living with type 2 diabetes using web-based or mHealth technologies.

The content of the DSMT-Q was informed by a previous study that undertook in-depth qualitative interviews $(n=15)$ with people living with type 2 diabetes in order to explore experiences of using web-based and mHealth technologies to manage their health [19]. The analysis identified seven themes as important to participants when using technology to support self-management. These themes were termed: information, understanding individual health and personal data, reaching and sustaining goals, minimizing disruption to daily life, reassurance, communicating with health care professionals, and coordinated care (see Kelly et al [19] for further details). Draft questionnaire items were constructed to reflect the seven themes, forming an item pool of 36 candidate items for the new questionnaire. The 36 questionnaire items were arranged in two parts. The first 22 items asked about the management of type 2 diabetes and the use of web-based or mHealth technology, while a further 14 items asked about the extent to which a specific technology helped to manage aspects of diabetes. This paper reports the item refinement and psychometric validation of the candidate items.

\section{Methods}

\section{Design and Ethics}

A mixed methods study, Phase 1 aimed to refine the 36 candidate DSMT-Q items drafted previously using cognitive debrief interviews, expert consultation, and public patient involvement (PPI) feedback. Phase 2 carried out a psychometric validation of the remaining candidate items using appropriate quantitative methods. Ethical approval for this research was granted by the Medical Sciences Inter Divisional Research Ethics Committee of the University of Oxford (reference R59651/RE001).

\section{Phase 1: Patient, Expert, and Public Item Refinement Cognitive Interviews of People Living With Type 2 Diabetes}

Thirty-six candidate items were pretested for ease of completion and understanding among people living with diabetes to ensure that items superficially made sense [20], and provided further support for content validity through ensuring that each theme identified in the qualitative interviews [19] was represented through the item content [21]. Participants were probed about their understanding of the proposed items and each item's relevance to self-managing health and the use of technology $[21,22]$. In cases where items were ambiguous or repetitive, they were amended or removed.

\section{Study Participants and Procedure}

Participants were aged 18 or over with a (self-reported) clinical diagnosis of type 2 diabetes and experience of using one or more diabetes-related web-based or mHealth technology. Participants who had previously taken part in an in-depth interview [19] to inform items and who consented to be contacted were emailed a participant information sheet. On agreeing to take part, participants could ask any questions about the research, asked to complete an online consent form, and given a link to the draft online survey containing the candidate items. Participants were given a GBP $£ 20$ (US \$24.92) voucher for their participation.

\section{Interviews}

Interviews were recorded and carried out over the telephone using a verbal probing method of cognitive interviewing to 
allow respondents an opportunity to give uninterrupted answers, which was then followed by a focused interview [23]. During the focused interview, participants were reminded of their answers to each item, and to gain a deeper understanding of their responses, the reasoning behind their answers was explored [24].

\section{Analysis}

Participant comments were summarized and collated in an Excel document (Microsoft) according to each instruction and questionnaire item, allowing within-case (how the item fits within the questionnaire as a whole) and between-case (interpretation and consistency of items across the sample) analysis. Interpretation difficulties or inconsistencies were discussed among authors, amended where appropriate, and retested.

\section{Expert Consultation}

An expert panel consisting of three survey development and patient-reported outcome experts, one survey expert and user engagement manager for a national diabetes program, two diabetes experts specializing in digital health, one professor of diabetic medicine, and one consultant physician in diabetes were invited to review the candidate DSMT-Q items via email. Consulting experts sought to evaluate items from both health professionals and survey developers' perspectives. Comments and feedback were received via email, and items amended where appropriate after discussion among the authors.

\section{PPI}

PPI representatives who were members of a volunteer list held by the Nuffield Department of Primary Care Health Sciences Coordinator of Patient \& Public Involvement were emailed an invite to take part in questionnaire feedback. Representatives were required to have type 2 diabetes, but as questions were designed to be answerable to both those who use technology to manage their health and those who do not, they were not required to have experience using technology to manage their health. Feedback was given over the telephone after representatives had been allowed to review the online survey.

\section{Phase 2: Psychometric Validation}

Two web-based surveys were formatted using Qualtric's survey software. Survey 1 included the refined DSMT-Q (21 items), the Diabetes Self-Efficacy Scale (DSES) [25], two questions on the use of technology and additional demographic questions.

The first question in Survey 1 asked the respondent if they had experience using web-based or mHealth technologies to manage their diabetes. They were shown an appropriate preamble to the DSMT-Q items: 'Think about the management of your type 2 diabetes over the past four weeks' or 'Think about the management of your type 2 diabetes, including your use of web-based or mobile technology, over the past four weeks.' All item stems remained the same regardless of the questionnaire preamble, and all responses were collated for item analysis.

The DSES is an eight-item scale to assess self-efficacy among people living with diabetes. The Diabetes Self-Efficacy Scale was developed for a randomized trial assessing community-based peer-led diabetes self-management [25]. Items were based on earlier chronic-disease self-efficacy scales [26]. The internal consistency of items is high $(\alpha=.85)$, and the scale demonstrates good test-retest reliability (intraclass correlation coefficient $[\mathrm{ICC}]=0.80$ ) [25].

Survey 2 aimed to assess the test-retest reliability of the DSMT-Q. The DSMT-Q, together with a transition item (whether the respondent's health has changed in the last two weeks), was therefore administered 2 weeks after Survey 1 had been completed.

\section{Procedure}

\section{Study Participants and Recruitment}

Participants were aged 18 or over with a (self-reported) clinical diagnosis of type 2 diabetes. Participants were recruited through a professional survey recruitment company. Eligible participants were provided with a participant information sheet and asked to confirm their consent to take part. Participants who confirmed they might be contacted again regarding the study while completing Survey 1 were sent an email 2 weeks later asking them to complete Survey 2.

We aimed to recruit 250 participants to complete Survey 1. Estimates suggest that meaningful psychometric tests require at least three times as many respondents as items [27], making this a conservative (large) sample size.

\section{Analysis}

Descriptive statistics were used to present demographic data. DSMT-Q items were subjected to several initial data checks to confirm their suitability for inclusion in further analysis. Decision rules for item removal included items with high floor and ceiling effects $(>40 \%$ of respondents selecting one of the extreme response options) [28,29] and items demonstrating a large number of weak correlations $(<0.2)$ with other items. Exploratory factor analysis (EFA) was performed to group items into conceptually sound sub-scales. Suitability of using EFA on the dataset was assessed through performing the Bartlett Test of Sphericity $(P<.05)$ [30] and calculating the Kaiser-Meyer-Olkin (KMO) statistic which has a recommended value of above 0.6 [31]. Factors with Eigenvalues $>1$ were rotated using an oblique, Direct Oblimin, rotation so that axes were not restricted to right angles, hence allowing correlation between the factors [32,33]. While both the Structure and Pattern matrices were used in interpreting output, and the Structure matrix offered primary guidance for interpretation [34].

Once domain structures were finalized, sub-scales floor and ceiling effects (>20\% of responses scoring 0 or 100) were examined, and population characteristics were explored to identify potential covariate factors impacting the final scales. Convergent validity was examined using Pearson correlation coefficients (r) to compare relationships between the DSMT-Q sub-scales and the DSES [33,35]. The DSES was hypothesized to have moderate correlations with DMST-Q scores. Internal consistency, an indication of a scale's reliability, was evaluated using the Cronbach alpha statistic (>0.7) [36]. External reliability was assessed using the test-retest procedure with the use of the ICC statistic to assess the stability of the scores [37]. 


\section{Results}

\section{Phase 1}

\section{Patient Interviews}

Eight participants took part in two rounds of cognitive interviews. In the first round, participants $(n=4)$ considered most questionnaire content to be relevant to the management of type 2 diabetes; however, considerable changes needed to be made to the arrangement of the items. Participants found it challenging to respond to the second set of mHealth specific items as they did not typically use one specific technology (for example, one mobile app) in isolation. Furthermore, many questionnaire items did not apply to every technology used, and it was, therefore, difficult for them to determine how they should respond. The second part of the questionnaire was removed, resulting in 12 items being deleted and 2 items, covering topics not already present in the first part, being restructured and included. Two further items, which asked about health care services, were deleted from part one due to participant feedback stating they were unrelated to the personal management of their type 2 diabetes. Twenty-two items were therefore retained.

Five items were amended following participant feedback. Two were amended to improve comprehension and clarity, one was amended to make it more suitable to the response options, one was changed to be more specific and capture the intended meaning better, and one item was changed to prevent duplication with a previous item.

In the second round of cognitive interviews, following participant $(n=4)$ feedback, four items were deleted as they were considered to duplicate existing content. Five items were amended to improve clarity, and one item was revised to apply to a broader population. Two items were considered too broad and were made into four items to improve accuracy. This process resulted in 20 items for expert consultation.

\section{Expert Consultation}

Twenty items were circulated to the expert group. Following feedback, two items were amended to improve language for low literacy groups. One item was amended to be more inclusive to a broader range of people. Six items were amended to improve clarity, and one item was split into two items to try and find the best way to capture reassurance, resulting in 21 items.

\section{Public Patient Involvement (PPI)}

PPI representatives $(n=4)$ gave feedback on the 21-item questionnaire. All items were understood by representatives; however, some showed a preference for the further granularity of items. For example, one representative expressed a wish to have separate questions for how easily they can monitor their blood glucose levels, diet, and exercise. This change was omitted due to the likelihood of high frequencies of not applicable or missing data.

\section{Phase 2}

\section{Characteristics}

Survey 1 participants included $104(41.6 \%)$ women and 146 $(58.4 \%)$ men. The average age was 55.9 years old (SD 16.4, range 69 years). The modal time since diagnosis of type 2 diabetes was between one and five years ago $(n=90,36 \%)$. Most participants $(n=232,92.8 \%)$ described themselves as White British. Further sample characteristics can be viewed in Table 1.

Table 1. Participant characteristics.

\begin{tabular}{ll}
\hline Characteristic & Value \\
\hline Sex, $\mathbf{n}(\boldsymbol{\%})$ & $146(58.4): 104(41.6)$ \\
$\quad$ Male: Female & $55.9(16.4,19-88$ years $)$ \\
Age (years) & \\
$\quad$ Mean (SD, range) & $27(10.8)$ \\
Time since diagnosis, $\mathbf{n}(\%)$ & $90(36.0)$ \\
$<12$ months & $56(22.4)$ \\
1-5 years & $77(30.8)$ \\
6-10 years & \\
$>10$ years & $232(92.8)$ \\
Ethnic group, $\mathbf{n}(\%)$ & $5(2.0)$ \\
White British & $4(1.6)$ \\
White (other) & $4(1.6)$ \\
Black African & $3(1.2)$ \\
Asian & $2(0.8)$ \\
Mixed race & \\
Other &
\end{tabular}




\section{Item Reduction and Scale Development}

Six items were removed due to ceiling effects of greater than $40 \%$. The KMO value for the remaining 15 items exceeded the recommended value of $0.6(\mathrm{KMO}=0.90)$, and the Bartlett Test of Sphericity reached statistical significance $(P<.01)$, indicating there was a correlation between the items. Three factors were initially extracted, explaining $69.1 \%$ of the variance. One factor consisted of two items and had a poor Cronbach alpha level of
0.40. These two items were removed, and a second-factor rotation extracted two factors, explaining $63.6 \%$ of the variance. See Table 2 for the factor structure and loadings. Factor 1, entitled Understanding individual health and making informed decisions, consisted of seven items and had a Cronbach alpha level of 0.90. The second factor, entitled Confidence to reach and sustain goals, consisted of six items and had a Cronbach alpha level of 0.88 .

Table 2. DSMT-Q factors and item loadings on the Structure matrix.

\begin{tabular}{|c|c|c|}
\hline \multirow[t]{2}{*}{ Item } & \multicolumn{2}{|c|}{ Factor loading $^{\mathrm{a}}$} \\
\hline & 1 & 2 \\
\hline I can easily monitor important information about my diabetes (for example, my blood glucose levels, diet, or exercise). & 0.813 & 0.645 \\
\hline I am able to make sense of any information that I monitor (for example, my blood glucose levels, diet, or exercise). & 0.812 & 0.639 \\
\hline I feel informed when making decisions about the management of my diabetes. & 0.804 & 0.553 \\
\hline $\begin{array}{l}\text { I am aware of the potential outcomes of any actions I take when managing my diabetes (for example, when taking } \\
\text { medications or choosing foods to eat). }\end{array}$ & 0.804 & 0.479 \\
\hline I have access to relevant information about my diabetes. & 0.796 & 0.443 \\
\hline I can usually identify the reasons behind any changes to my blood glucose levels. & 0.757 & 0.441 \\
\hline I understand how my body reacts to exercise. & 0.728 & 0.612 \\
\hline I feel reassured that I am managing my diabetes well. & 0.546 & 0.865 \\
\hline I think my diabetes is under control. & 0.509 & 0.856 \\
\hline I can achieve any personal goals I set when managing my diabetes. & 0.491 & 0.807 \\
\hline I am motivated to carry out routines to manage my diabetes (for example, take medication, exercise). & 0.584 & 0.775 \\
\hline I know when to take action to maintain my desired blood glucose levels. & 0.705 & 0.726 \\
\hline I feel motivated to play an active role in my diabetes management. & 0.564 & 0.627 \\
\hline
\end{tabular}

${ }^{\mathrm{a}}$ Rotation Method: Oblimin with Kaiser Normalization.

\section{Scale Distributions and Validation}

Each scale was transformed to a 0-100 metric, where 0 indicated low levels of self-management, and 100 indicated high levels of self-management of type 2 diabetes. Scale scores were calculated by summing the final response values in each sub-scale and dividing the summed score by the maximum scale score. The raw scale score was then transformed into a 0-100 metric by multiplying the raw score by 100 . Scale distribution statistics are reported in Table 3. Neither scale exhibited floor or ceiling effects, which was considered to be $>20 \%$ of responses, achieving the minimum or maximum score. Minimal respondents achieved scores of 0 , while $10.8 \%(n=27)$ of Factor 1 scores and $10.4 \%(n=26)$ of Factor 2 scores achieved the maximum score of 100 .

Table 3. Scale score descriptive statistics $(\mathrm{N}=250)$.

\begin{tabular}{|c|c|c|c|c|c|c|c|}
\hline Scale & Minimum & Maximum & Mean (SD) & Skewness & Kurtosis & $\mathrm{ICC}^{\mathrm{a}}, \mathrm{n}=113$ & $P$ value \\
\hline $\begin{array}{l}\text { Factor 1: Understanding } \\
\text { Individual Health and } \\
\text { making informed decisions }\end{array}$ & 0 & 100 & $75.3(18.1)$ & -0.89 & 1.19 & 0.89 & $<.001$ \\
\hline $\begin{array}{l}\text { Factor 2: Confidence to } \\
\text { reach and sustain goals }\end{array}$ & 0 & 100 & $75.4(17.7)$ & -0.95 & 1.43 & 0.86 & $<.001$ \\
\hline DSES $^{b}$ & 0 & 10 & 7.7 (1.9) & -1.01 & 1.00 & $N / A^{c}$ & N/A \\
\hline
\end{tabular}

\footnotetext{
${ }^{\mathrm{a}}$ Absolute agreement.

${ }^{\mathrm{b}}$ Diabetes Self-Efficacy Scale.

${ }^{\mathrm{c}}$ N/A: not applicable.
}

Relationships between each DSMT-Q scale and a range of differences were found for either sex (Factor 1: $t_{248}=-0.54$, potential covariate factors were examined. No significant $P=.59$ and Factor $\left.2: \mathrm{t}_{248}=-0.35, P=.72\right)$ or age $(\mathrm{n}=248$, Factor 
1: $r=-0.11, P=.10$ and Factor 2: $r=-0.06, P=.31)$ among either sub-scale scores. Nonparametric tests to examine sex (Mann-Whitney $U$ test of significance; Factor $1, P=.59$, Factor $2=0.71)$ and age $(n=248$; Factor $1: \rho=-1.37, P=.03$, Factor 2 : $\rho=-0.09, P=.15$ ) also demonstrated no significant differences. No significant differences were observed for time since diagnosis for using parametric (analysis of variance; Factor 1: $F_{246}=2.14, P=.10$, Factor 2: $F_{246}=1.891, P=.13$ ) or nonparametric tests (Kruskal-Wallis k independent samples; Factor 1: $P=.13$, Factor 2: $P=.15)$.

Relationships between the DMST-Q scales and the DSES scale were examined to assess convergent validity. Correlations were high (Factor 1, $r=0.67, P<.001$ and Factor 2, $r=0.75, P<.001$ ), indicating the scales were tapping into similar but different concepts.

As predicted, those who did use technology to support self-management scored more highly on both new DMST-Q scales. For Factor 1, those using technology to support self-management $(n=92)$ had a mean score of 78.81 (SD 16.64), while those who did not use technology $(n=158)$ scored 72.60 (SD 18.42, $\mathrm{t}_{248}=3.09, P=.002$ ). For Factor 2, those using technology to support self-management $(n=92)$ had a mean score of 80.21 (SD 14.61), while those who did not use technology $(\mathrm{n}=158)$ scored $72.52\left(\mathrm{SD} 18.73, \mathrm{t}_{248}=3.38, P<.001\right)$.

Factor 1 and 2 also demonstrated good test-retest reliability with ICC values, for those who had indicated their health had remained the same compared to two weeks ago $(n=113)$, equal to $0.78(P<.001)$ and $0.74(P<.001)$, respectively.

\section{Discussion}

\section{Principal Findings}

This paper reports the development of a new instrument, the DSMT-Q, to assess self-management in people living with type 2 diabetes using web-based and mHealth technologies to manage their health. Phase 1 used patient and expert feedback to reduce and refine 36 candidate items to 21 items. Phase 2 further refined items using EFA and confirmed the presence of two sub-scales. The first sub-scale contained seven items and was entitled "Understanding individual health and making informed decisions." Understanding individual health to make informed decisions was found to be extremely important in the preliminary qualitative work to support this research [19]. It is further supported by other diabetes research that links logging, visualizing, and understanding individual health to acquire new knowledge and make changes to behavior [38]. Similar conclusions can also be found in other condition groups, including COPD, where mHealth applications have also been used to support self-management [39].

The second subscale contained six items and was entitled "Confidence to reach and sustain goals." Although the preliminary qualitative work carried out to inform this instrument supports the grouping of these items, it is also supported through early research, which links the potential of web-based interventions to patient empowerment [40]. Gaining confidence and taking ownership to reach personal goals through monitoring physical activity on a mobile app has also been demonstrated among patients in the primary care setting [41].

Statistical analyses confirmed the DSMT-Q subscales were highly related to the DSES scale scores and therefore providing evidence of similar, yet distinct constructs. As expected, no significant differences were found for sex or age. Respondents who indicated that they did use technology to manage their health scored more highly on both scales indicating that the items can differentiate between technology and nontechnology users. Internal and external reliability was demonstrated for both scales.

The methods used in this study enabled input from both people living with type 2 diabetes and experts during the refinement of the new instrument. Incorporating the patient throughout the stages of instrument development is essential to ensure the user's perspective is accurately reflected $[18,42]$, and the inclusion of experts helped to ensure that the instrument would be of use in a range of applied settings.

Questionnaire items were also designed to be used in a comparator, nonintervention group to maximize utility of the measure. Although the items are based on themes identified as relevant to the use of web-based and mHealth technologies, they are also applicable and worded appropriately for those who are not using technology to manage their health. As such, this instrument may be used in a variety of contexts where a comparator group receives standard care or other technology or non-technology-based resources. In contrast with other technology-specific instruments that include references to a specific device or website [43], the wording of the items allows for the responder to use multiple resources, for example, mobile apps plus wearable devices.

\section{Limitations}

There are a few limitations to this study regarding the participant sample. First, Black, Asian, and minority ethnic groups were underrepresented within the sample. Second, it should be noted that the use of survey panels to recruit participants for surveys is in its relative infancy in the patient-reported outcome setting; however, it is a method that has been incorporated into other research settings, such as health economics [44]. With regard to measurement properties, further longitudinal research is required to demonstrate the instrument's sensitivity to change.

\section{Conclusions}

This paper reports two phases of the development of a new instrument-the DSMT-Q. Analyses confirmed good psychometric properties in the DSMT-Q scales. This tool is fully compliant with relevant regulatory bodies, such as the FDA and EMA, and will facilitate the measurement of self-management in people living with type 2 diabetes using web-based or mHealth technologies. 


\section{Acknowledgments}

LK contributed to the study design, carried out the survey, and had a lead role in the analysis. CJ and DM contributed to the study design and analysis. All authors contributed to and approved the final manuscript.

The authors would like to thank Diabetes UK and Diabetes Support Forum UK, who helped with recruitment for the Phase 1 interviews. The authors would also like to thank the participants who volunteered their time to take part in the study. The authors would like to thank all the expert reviewers who volunteered their time.

This research was funded by the National Institute for Health Research (NIHR) Collaboration for Leadership in Applied Health Research and Care Oxford at Oxford Health NHS Foundation Trust. The views expressed are those of the author(s) and not necessarily those of the NHS, the NIHR, or the Department of Health and Social Care. Research costs were funded internally within the Health Service Research Unit, Nuffield Department of Population Health, University of Oxford.

\section{Conflicts of Interest}

None declared.

\section{References}

1. Diabetes Prevalence 2018. Diabetes UK. URL: https://www.diabetes.org.uk/professionals/position-statements-reports/ statistics/diabetes-prevalence-2018 [accessed 2020-03-01]

2. Us, diabetes and a lot of facts and stats. Diabetes UK. URL: https://www.diabetes.org.uk/resources-s3/2019-02/1362B Facts and stats Update Jan 2019 LOW RES EXTERNAL.pdf [accessed 2020-03-01]

3. Type 2 diabetes in adults: management. NICE guideline NG28 Internet. 2017. URL: https://www.nice.org.uk/guidance/ ng28/chapter/1-Recommendations [accessed 2020-03-01]

4. Hex N, Bartlett C, Wright D, Taylor M, Varley D. Estimating the current and future costs of Type 1 and Type 2 diabetes in the UK, including direct health costs and indirect societal and productivity costs. Diabet Med 2012 Jul;29(7):855-862. [doi: 10.1111/j.1464-5491.2012.03698.x] [Medline: 22537247]

5. Kerr D, Axelrod C, Hoppe C, Klonoff DC. Diabetes and technology in 2030: a utopian or dystopian future? Diabet Med 2018 Apr;35(4):498-503. [doi: 10.1111/dme.13586] [Medline: 29356078]

6. King D, Toobert D, Portz J, Strycker L, Doty A, Martin C. What patients want: relevant health information technology for diabetes self-management. Health Technol 2012;2(3):147. [doi: 10.1007/s12553-012-0022-7]

7. Yu Y, Yan Q, Li H, Li H, Wang L, Wang H, et al. Effects of mobile phone application combined with or without self-monitoring of blood glucose on glycemic control in patients with diabetes: A randomized controlled trial. J Diabetes Investig 2019 Sep;10(5):1365-1371 [FREE Full text] [doi: 10.1111/jdi.13031] [Medline: 30815973]

8. Pal K, Eastwood SV, Michie S, Farmer AJ, Barnard ML, Peacock R, et al. Computer-based diabetes self-management interventions for adults with type 2 diabetes mellitus. Cochrane Database Syst Rev 2013 Mar 28(3):CD008776 [FREE Full text] [doi: 10.1002/14651858.CD008776.pub2] [Medline: 23543567]

9. Schmitt A, Gahr A, Hermanns N, Kulzer B, Huber J, Haak T. The Diabetes Self-Management Questionnaire (DSMQ): development and evaluation of an instrument to assess diabetes self-care activities associated with glycaemic control. Health Qual Life Outcomes 2013 Aug 13;11:138 [FREE Full text] [doi: 10.1186/1477-7525-11-138] [Medline: 23937988]

10. Murray E, Sweeting M, Dack C, Pal K, Modrow K, Hudda M, et al. Web-based self-management support for people with type 2 diabetes (HeLP-Diabetes): randomised controlled trial in English primary care. BMJ Open 2017 Sep 27;7(9):e016009 [FREE Full text] [doi: 10.1136/bmjopen-2017-016009] [Medline: 28954789]

11. Whitehead LC, Crowe MT, Carter JD, Maskill VR, Carlyle D, Bugge C, et al. A nurse-led interdisciplinary approach to promote self-management of type 2 diabetes: a process evaluation of post-intervention experiences. J Eval Clin Pract 2017 Apr 15;23(2):264-271. [doi: 10.1111/jep.12594] [Medline: 27417302]

12. Kebede M, Pischke C. Corrigendum: Popular Diabetes Apps and the Impact of Diabetes App Use on Self-Care Behaviour: A Survey Among the Digital Community of Persons With Diabetes on Social Media. Front Endocrinol (Lausanne) 2019;10:220 [FREE Full text] [doi: 10.3389/fendo.2019.00220] [Medline: 31024457]

13. Chen L, Chuang L, Chang C, Wang C, Wang I, Chung Y, et al. Evaluating self-management behaviors of diabetic patients in a telehealthcare program: longitudinal study over 18 months. J Med Internet Res 2013 Dec 09;15(12):e266 [FREE Full text] [doi: 10.2196/jmir.2699] [Medline: 24323283]

14. Zhang L, He X, Shen Y, Yu H, Pan J, Zhu W, et al. Effectiveness of Smartphone App-Based Interactive Management on Glycemic Control in Chinese Patients With Poorly Controlled Diabetes: Randomized Controlled Trial. J Med Internet Res 2019 Dec 09;21(12):e15401 [FREE Full text] [doi: 10.2196/15401] [Medline: 31815677]

15. Veazie S, Winchell K, Gilbert J, Paynter R, Ivlev I, Eden KB, et al. Rapid Evidence Review of Mobile Applications for Self-management of Diabetes. J Gen Intern Med 2018 Jul;33(7):1167-1176 [FREE Full text] [doi:

10.1007/s11606-018-4410-1] [Medline: 29740786] 
16. McKay FH, Cheng C, Wright A, Shill J, Stephens H, Uccellini M. Evaluating mobile phone applications for health behaviour change: A systematic review. J Telemed Telecare 2018 Jan;24(1):22-30. [doi: 10.1177/1357633X16673538] [Medline: 27760883]

17. FDA. US Department of Health and Human Services Food and Drug Administration. Guidance for industry: patient-reported outcome measures: use in medical product development to support labeling claims. Internet. 2009. URL: https://www. fda.gov/regulatory-information/search-fda-guidance-documents/ patient-reported-outcome-measures-use-medical-product-development-support-labeling-claims [accessed 2020-02-11]

18. EMA. Reflection paper on the regulatory guidance for the use of health-related quality of life (HRQL) measures in the evaluation of medicinal products Internet. European Medicine Agency. 2004. URL: https://www.ema.europa.eu/en/ regulatory-guidance-use-health-related-quality-life-hrql-measures-evaluation-medicinal-products [accessed 2020-02-11]

19. Kelly L, Jenkinson C, Morley D. Experiences of Using Web-Based and Mobile Technologies to Support Self-Management of Type 2 Diabetes: Qualitative Study. JMIR Diabetes 2018 May 11;3(2):e9 [FREE Full text] [doi: 10.2196/diabetes.9743] [Medline: 30291098$]$

20. Jenkinson C, McGee H. Patient assessed outcomes: measuring health status quality of life. In: Jenkinson C, editor. Assess Eval Heal Med Care A Methods Text. Oxford: Open University Press; 1997.

21. Bowling A. Measuring Health: A review of quality of life measurement scales. Third. Maidenhead: Open University Press; 2005.

22. Revicki DA, Erickson PA, Sloan JA, Dueck A, Guess H, Santanello NC, Mayo/FDA Patient-Reported Outcomes Consensus Meeting Group. Interpreting and reporting results based on patient-reported outcomes. Value Health 2007;10 Suppl 2:S116-S124 [FREE Full text] [doi: 10.1111/j.1524-4733.2007.00274.x] [Medline: 17995470]

23. Willis G. Cognitive Interviewing in Practice: Think-Aloud, Verbal Probing, and Other Techniques. Cognitive Interviewing. Thousand Oaks, USA: Sage Publications; 2005.

24. Willis G. Analysis of the Cognitive Interview in Questionnaire Design. Oxford University Press 2015.

25. Lorig K, Ritter PL, Villa FJ, Armas J. Community-based peer-led diabetes self-management: a randomized trial. Diabetes Educ 2009;35(4):641-651. [doi: 10.1177/0145721709335006] [Medline: 19407333]

26. Lorig K. Outcome Measures for Health Education and Other Health Care Interventions. In: Outcome Measures for Health Education and Other Health Care Interventions. London: SAGE Publications; 1996.

27. Kline P. A Psychometric Primer. London: Free Association Books; 2000.

28. Jenkinson C, Fitzpatrick R, Peto V, Dummett S, Morley D, Saunders P. The Parkinson's Disease Questionnaire: User Manual. Oxford: Health Services Research Unit; 2012.

29. Peto V, Jenkinson C, Fitzpatrick R, Greenhall R. The development and validation of a short measure of functioning and well being for individuals with Parkinson's disease. Qual Life Res 1995 Jun;4(3):241-248. [doi: 10.1007/bf02260863] [Medline: 7613534]

30. Puvvada SD, Funkhouser WK, Greene K, Deal A, Chu H, Baldwin AS, et al. NF-kB and Bcl-3 activation are prognostic in metastatic colorectal cancer. Oncology 2010;78(3-4):181-188 [FREE Full text] [doi: 10.1159/000313697] [Medline: 20414006]

31. Kaiser HF, Rice J. Little Jiffy, Mark IV. Educational and Psychological Measurement 2016 Jul 02;34(1):111-117. [doi: $\underline{10.1177 / 001316447403400115]}$

32. Matsunaga M. How to Factor-Analyze Your Data Right: Do's, Don'ts, and How-To's. Int J Psychol Res 2010;3(1):110.

33. Norman G, Streiner D. Biostatistics: The Bare Essentials. London: B. C. Decker; 2000.

34. Pett M, Lackey N, Sullivan J. Making Sense of Factor Analysis: The Use of Factor Analysis for Instrument Development in Health Care Research. London: SAGE Publications; 2003.

35. Williams G. In: Detels R, Beaglehole R, Lansang MA, Gulliford M, editors. Statistical methods. New York: Oxford University Press; 2009.

36. Cronbach LJ. Coefficient alpha and the internal structure of tests. Psychometrika 1951 Sep;16(3):297-334. [doi: 10.1007/bf02310555]

37. Nunnally J, Bernstein I. Psychometric Theory. 3rd ed. New York: McGraw-Hill; 1994.

38. Burford SJ, Park S, Dawda P. Small Data and Its Visualization for Diabetes Self-Management: Qualitative Study. JMIR Diabetes 2019 Aug 13;4(3):e10324 [FREE Full text] [doi: 10.2196/10324] [Medline: 31411137]

39. Williams V, Price J, Hardinge M, Tarassenko L, Farmer A. Using a mobile health application to support self-management in COPD: a qualitative study. Br J Gen Pract 2014 Jul;64(624):e392-e400 [FREE Full text] [doi: 10.3399/bjgp14X680473] [Medline: 24982491]

40. Samoocha D, Bruinvels DJ, Elbers NA, Anema JR, van der Beek AJ. Effectiveness of web-based interventions on patient empowerment: a systematic review and meta-analysis. J Med Internet Res 2010 Jun 24;12(2):e23 [FREE Full text] [doi: 10.2196/jmir.1286] [Medline: 20581001]

41. Casey M, Hayes PS, Glynn F, OLaighin G, Heaney D, Murphy AW, et al. Patients' experiences of using a smartphone application to increase physical activity: the SMART MOVE qualitative study in primary care. Br J Gen Pract 2014 Aug;64(625):e500-e508 [FREE Full text] [doi: 10.3399/bjgp14X680989] [Medline: 25071063] 
42. Speight J, Barendse SM. FDA guidance on patient reported outcomes. BMJ 2010 Jun 21;340:c2921. [doi: 10.1136/bmj.c2921] [Medline: 20566597]

43. Kelly L, Ziebland S, Jenkinson C. Measuring the effects of online health information: Scale validation for the e-Health Impact Questionnaire. Patient Educ Couns 2015 Nov;98(11):1418-1424 [FREE Full text] [doi: 10.1016/j.pec.2015.06.008] [Medline: 26162953]

44. Fletcher BR, Rowe R, Hollowell J, Scanlon M, Hinton L, Rivero-Arias O. Exploring women's preferences for birth settings in England: A discrete choice experiment. PLoS One 2019;14(4):e0215098 [FREE Full text] [doi: 10.1371/journal.pone.0215098] [Medline: $\underline{\text { 30973919] }}$

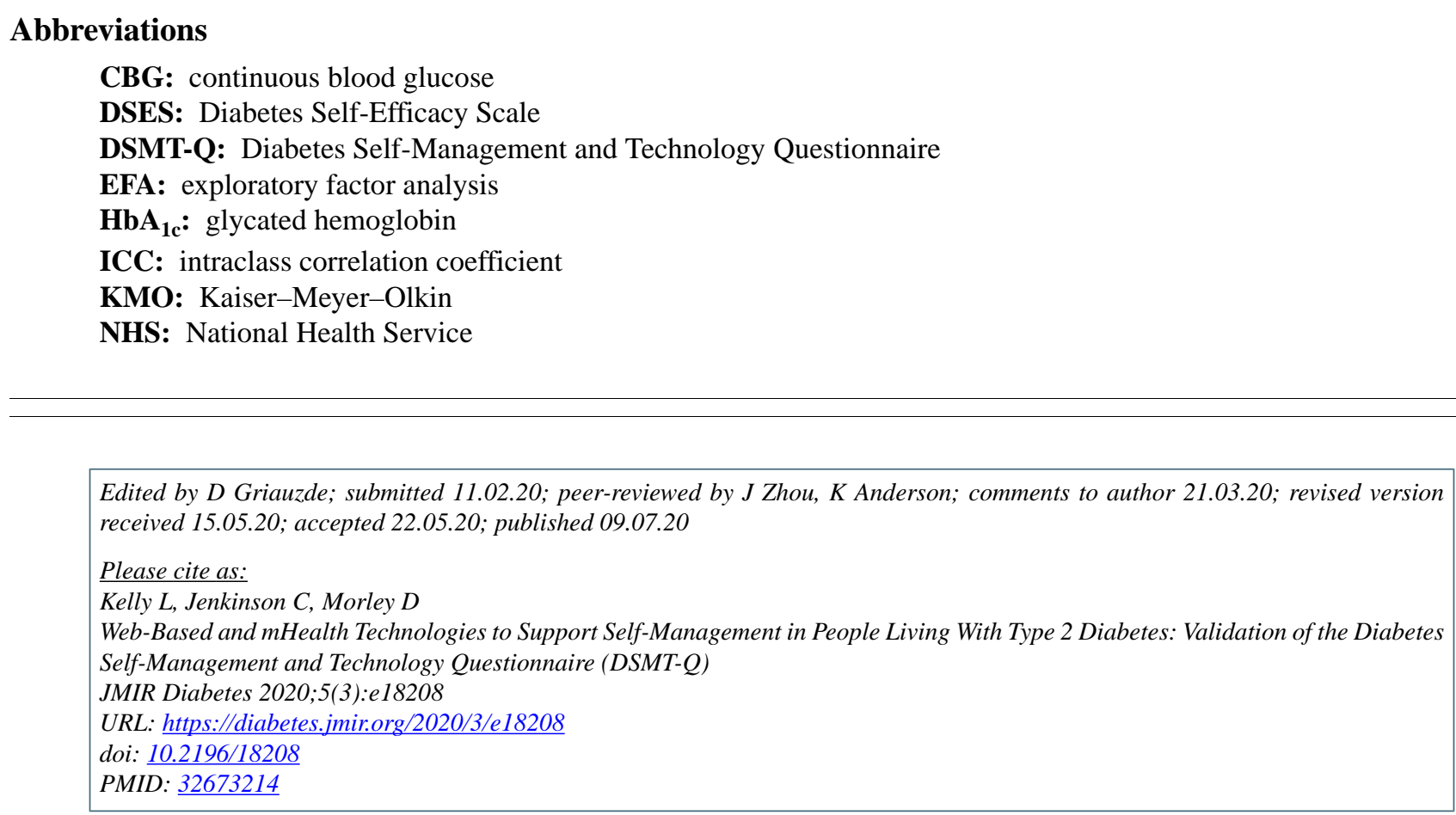

(CLaura Kelly, Crispin Jenkinson, David Morley. Originally published in JMIR Diabetes (http://diabetes.jmir.org), 09.07.2020. This is an open-access article distributed under the terms of the Creative Commons Attribution License (https://creativecommons.org/licenses/by/4.0/), which permits unrestricted use, distribution, and reproduction in any medium, provided the original work, first published in JMIR Diabetes, is properly cited. The complete bibliographic information, a link to the original publication on http://diabetes.jmir.org/, as well as this copyright and license information must be included. 